\title{
LABIRINTITE CONSEQUENTE AO USO DE DIFENILHIDANTOINA
}

\author{
ENEIDA BAPTISTETE MATARAZZO*
}

Em publicação recente, foi feita, pela autora, revisão dos efeitos colaterais provocados pelo uso de medicamentos anti-epiléticos ${ }^{1}$, entre os quais a difenilhidantoina; na bibliografia referente a este último medicamento foram mencionados os seguintes sintomas: hiperplasia gengival, eritema escarlatiniforme, púrpura, dermatite esfoliativa. estomatite, queratose, sensação de peso no estômago, gastralgia, náusea, vômitos, constipação intestinal, anorexia, tontura, cefaléia, ataxia, tremor đas extremidades, balanço da cabeça, diplopia, nistagmo, embaçamento da visão, dor ocular, ptose palpebral, ansiedade, irritabilidade, sonolência, excitação, distúrbios dạ memória, ilusões, alucinações, sensação de levitação, fadiga, mal-estar, discrasias sanguíneas, anemia megaloblástica, agranulocitose, hepatite, hirsutismo, alterações de tipo cerebelar que podem ser irreversíveis e, ainda, uma tríade sintomática: enantema, conjuntivite pseudomembranosa e queratite (síndrome de Stevens-Johnson).

Nos livros e trabalhos incluidos nesta revisão não foi mencionada a possibilidade de ser provocado um quadro de labirintite pelo uso da difenilhidantoina. Por esta razão, foi considerada oportuna a publicação do caso clínico que será descrito a seguir.

\section{OBSERVAÇAO}

M. R. brasileiro, branco, casado, 36 anos, pertence a familia de classe média e refere, entre parentes de primciro grau, alguns casos de epilepsia. O paciente nasceu em condiçñes normais e teve desenvolvimento satisfatório, não referindo, na infancia, manifestações que pudessem ser atribuídas à єpilepsia. Aos 16 anos, teve crise convulsiva de tipo tónico-clónico; consultou clínico geral que prescreveu fenobarbital (100 mg v.o., diariamente). Tomou um mês a medicação, interrompendo o tratamento por sua iniciativa. Aos 32 anos, sem causa aparente desencadeante, teve nova crise convulsiva de tipo tônico-clónico, durante 0 sono; foi entăo submetido a vários exames - clínico geral, neurológico, exame de líquido cefalorraquidiano, radiografia simples de crânio e hemograma - todos resultando normais. Fez, na mesma ocasião, exame eletrencefalográfico que revelou a existência de foco convulsígeno na área frontotemporal esquerda. O neurologista que o tratava prescreveu $200 \mathrm{mg}$ diários, por via oral, de difenilhidantoina. No 40 dia de tratamento o paciente começou a apresentar sensação de formigamento no rosto e nas mãos. Admitindo que fosse efeito do remédio, seu médico substítuiu-o por carbamazepina, na dose dí́ria de $200 \mathrm{mg}$, por via oral. Este tratamento foi mantido sem que surgissem efeitos colaterais ou mani-

* Prof. Assistente do Departamento de Neuro-Psiquiatria da Faculdade de Medicina da Universidade de São Paulo 
festações epilćticas durante um ano, findo o qual foi realizado novo eletrencefalograma. Como o resulta:-:o deste foi normal, o neurologista suspendeu a medicaçăo e deu alta so paciente (sic). Este passou bem nos anos seguintes, tendo apenas leves crises de cefaléía e de tontura. Aos 35 anos. também sem causa desencadeante aparente. teve, durante uma reunião festiva no local de trabalho, a terceira crise, do tipo Grande Mal. Submeteu-se novamente a exame eletrencefalográfico e, como o resultado foi semelhante ao anterior, reiniciou tratamento anti-epilético com carbamazepina. Em junho de 1976 teve meningite linfocitária benigna e ficou hospitalizado três semanas. D médico que o tratou decidiu. sem explicar o motivo ao paciente, substituir a carbamazepina por difenilhidantoina (100 $\mathrm{mg}$ ) e fenobarbital (100 $\mathrm{mg})$, diariamente, por via oral. Em julho de 1976 (um mês após o início dessa terapêutica) o paciente começou a apresentar crises labirínticas, de tipo rotatório, quando virava bruscamente ou inclinava a sabeça para a esquerda: percebendo ser esta a causa das crises, conseguia evitá-las movendo com cuidado a cabeça ou evitando incliná-la. Entretanto, ao fim de mais dois meses esse cuidado já não era suficiente para neutralizá-las, pois se desencadeavam com pequenas mudanđas na postura; além disto perdeu o apetite e começou a ter náusea cada vez mais intensa, seguida quase sempre de vômitos após as refeiçóes; não sentia, porém, dor abdominal. Seu estado físico geral decaiu, năo lhe sendo mais possivel realizar seu trabalho de escriturário. Consultou, então, médico otorrinolaringologista que, após os exames especializałos, fez o diagnóstico de labirintite e prescreveu-lhe tratamento especifico; além disto, substituiu os medicamentos anti- epiléticos por um outro produto, também anti-epilético, composto de difenilhidantoina (50 $\mathrm{mg}$ ), prominal (50 $\mathrm{mg}$ ) e fenobarbital $(50 \mathrm{mg})$. Apesar do tratamento intensivo para a labirintite, o quadro foi-se agravando, com crises vertiginosas mais intensas e vómitos tão frequentes que por três vezes, no espaço de dois meses, teve que ser hospitalizado e hidratado por via venosa. Nesse periodo submeteu-se a novos exames (fundo de olho, radiografia de crânio, exame de líquido cefalorraquiano) para afastar a possibilidade de um processo cerebral em evolução. Ante o resultado normal dos exames e o insucesso do tratamento para labirintite, o otorrinolaringologista aventou a hipótese de que fatores psícológicos interferissem no quadro clínico e por isso recomendou uma consulta psiquiátrica. acrescentando, porém, ao msemo tempo, $30 \mathrm{mg}$ diários de diazepan, v.o.

O paciente foi examinado pela autora deste trabalho em dezembro de 1976. Além das queixas subjetivas - crises vertiginosas relacionadas com a rotaçăo ou inclinação da cabeça para a esquerła, anorexia, náusea constante, sensaçăo de mal-estar e astenia acentuada - foi observado, no exame, comprometimento do nível da consciencia, sob a forma de leve torpor: o pensamento mostrava-se um pouco lentificado e a elaboração mental era realizada mediante visivel esforço; a memória de evocaçáo encontrava-se diminuída e o humor deprimido. O paciente revelava, de fato, a existéncia de conflitos de natureza sentimental e moral, porém em nível consciente e de existência bem anterior ao início da doença, năo parecendo, pelo que fol apurado, terem influência significativa sobre a sintomatologia atual e nem mesmo sobre o humor depressivo, que parecia ser decorrente da sua sensação física de intenso mal-estar, da desagradável inatividade a que a doença o obrigava e da pouca esperança em sua cura. $O$ exame neurológico revelou apenas ligeira alteração da marcha, com alargamento da base de sustentaçåo e com discreto desvio para a esquerda.

Em face dos dados da anamnese e do exame, a hipótese diagnóstica que pareceu mais provável foi a de uma intoxicaçăo pela difenilhidantoina, para a qual o paciente já revelara anteriormente sinais de intolerancia. Foram suspensos todos os medicamentos em uso e prescrito unicamente fenobarbital, na dose diária de $100 \mathrm{mg}$. ., .0 . Esta orientação terapêtica produziu melhora lenta e progressiva, mas não impediu que no 30 dia de tratamento o paciente fosse hospitalizado pela quarta vez, para ser hidratado em consequência dos vômitos. Ao fím de duas semanas, estes, e também a náusea. haviam desaparecido, o apetite voltara ao normal e o estado geral melhorara de forma nítida. Já năo apresentava torpor, nem lentificaçăo do pensamento. As crises labiríntivas foram se espaçando e diminuindo de intensidade, porém só cessaram por completo cerca de dois meses e meio após a suspensăo do tratamento anterior. Com uso exclusivo 
de fenobarbital, na dose de $100 \mathrm{mg}$ diários, o paciente permanecia bem até o mês dṇ maio de 1977, época em que foi feito este trabalho; executava sem dificuldade suas funções de escriturário e não apresentava quaisquer queixas de natureza fisiça ou mental.

\section{COMENTARIOS H CONCLUSEES}

$O$ caso clínico aqui relatado permite deduzir que 0 uso da difenilhidantoina foi responsável pela manifestação de labirintite, de sintomatologia intensa e de consequências graves para o paciente. Esta afirmação baseou-se nos seguintes fatos: 1) a difenilhidantoina foi introduzida como medicamento exclusivo no primeiro tratamento anti-epilético a que o paciente se submeteu e produziu, já nos primeiros dias, sinais de intolerância; 2) a carbamazepina, também de ação anti-epilética, controlou o quadro clinico sem produzir efeitos indesejáveis; 3 ) o reinicio do uso de difenilhidantoina, associada ao fenobarbital, foi seguido de manifestações clínicas de labirintite, que se mostraram rebeldes ao tratamento específico; 4) a suspensão da difenilhidantoina, com manutenção do fenobarbital, levou ao desaparecimento desse quadro clínico, em prazo curto.

Embora não se possa afirmar, pode-se supor que o médico otorrinolaringologista, ao substituir o tratamento anti-epilético, tenha pretendido afastar uma possivel causa de labirintite, que sabidamente pode ser provocada por intolerância medicamentosa; nesse cas), entretanto, pouco afeito aos medicamentos anti-epiléticos, que não são de uso em sua especialidade, não deve ter-se dado conta de que o novo produto prescrito*, embora de nome comercial muito diferente, continha duas das drogas em uso pelo paciente. Em trabalhos anteriores 1,2 a autora tem insistido na inconveniência de se prescrever associação de medicamentos anti-epiléticos no início de um tratamento sem testar isoladamente as diferentes drogas prescritas, seja para avaliar sua eficácia, seja para verificar a tolerância ao seu uso. O presente caso é um reforço quanto à necessidade de. se atender a essa norma da terapêutica anti-epilética.

Outro aspecto importante deste relato clínico é que o paciente, que vinha evoluindo bem com determinado tratamento anti-epilético, teve sintomas graves quando este foi modificado por decisão médica e sem razão aparente para justificar tal atitude. Uma vez mais se mostra válido o preceito médico que contraindica a alteração de um tratamento enquanto ele beneficia o paciente, alcançando o objetivo terapêutico almejado, sem produzir efeitos indesejáveis.

$O$ caso clínico relatado neste trabalho permite concluir que, na extensa relação dos efeitos colaterais decorrentes do uso de difenilhidantoina, deve ser incluida a labirintite.

\section{RESUMO}

É relatado o caso de paciente epilético que, aos 16 anos de idade, ao tazer uso de difenilhidantoina, apresentou, já nos primeiros dias, sinais de intolerância, com sensação de formigamento das extremidades. Aos 36 anos voltou a fazer

* Comital-L 
uso desse mesmo medicamento e apresentou sintomas de labirintite, tendo crises de tipo rotatório quando inclinava a cabeça para a esquerda ou a movia bruscamente. O tratamento especifico para labirintite, orientado por otorrinolaringologista, foi ineficaz e o quadro clínico agravou-se progressivamente. Ao fim de seis meses seu exame psíquico revelava leve torpor, lentificação do raciocínio, incapacidade para o trabalho e depressão reativa, observando-se, do ponto de vista neurológico, discreto desvio da marcha para a esquerda e discreto aumento da base de sustentação. Além disto referia a existência de crises rotatórias e vômitos tão frequente's çue nos últimos dois meses piecisou ser hospitalizado algumas vezes, para ser hidratado. A suspensão da difenilhidantoina com manutenção exclusiva de fenobarbital (do qual também já vinha fazendo uso), determinuu regressão rápida dos sintomas citados. Tal fato permitiu concluir que a labirintite foi provơcada pelo uso da difenilhidantoina e deve ser incluida na extensa relação de efeitos colaterais provocados por essa droga.

\section{SUMMARY}

\section{Labyrinthitis provoked by the use of diplierilhydantoin: a case report}

This report describes the case of an epilepic patient who, at the age of 16 , when he started to use diphenilhydantoin, showed, in the very first days, signs of intolerance, with sensation of tingling in the extremities. At the age of 36 , the patient again made use of this drug and developed symptoms of labyrinthitis, with crises of a rotatory type when inclining his head to the left or when moving it abruptly. The specific treatment for labyrinthitis recomended by an otorhinotaryngologist proved to be ineffective and the clinical picture aggravated progressively. Six months later, the patient's psychic examination revealed a slight torpor, slowness of reasoning, inability to work and a reactive depression. There has also been observed, from the neurological point of view, a slight deviation of the gait towards the left, and a slight enlargement in the base ci sustentation. Besides this, vertiginous crises and vomits were so frequent that in the last two months he has had to be hospitalized several times to be hydrated. The interruption of diphenilhydantoin and the continuation of phenobarbital as the exclusive medication (he was already making use of it), determined the rapid regression of the symptoms mentioned. Such facts permitted us to conclude that the labyrinthitis was provoked by the use of diphenilhydantoin and must be included in the extensive list of side effects provoked by this drug.

\section{REFERENCIAS}

1. MATARAZZO, E. B. - Efeitos colaterais dos medicamentos antiepiléticos. Rev. Ass. Med. Bras. $22: 139$, 1976.

2. MATARAZZO, E. B. \& MATSUMOTO J. - Efeitos colaterais e desacertos na terapêutica anti-epilética. Arq. Neuro-Psiquiat. (Såo Paulo) 33:353, 1975.

Hospital de Psiquiatria, Faculdade de Medicina - Universidade de são Paulo Caixa Posial 8391 - 01Cco sao Paulo, SP - Brasil. 